Brit. J. vener. Dis. (1958), 34, 91.

\title{
PRELIMINARY EVALUATION OF THE TREPONEMAL WASSERMANN REACTION (T.W.R.)*
}

\author{
BY \\ I. N. ORPWOOD PRICE \\ V.D. Reference Laboratory (M.R.C.), London Hospital Research Laboratories, Whitechapel, London
}

Most of the relatively few papers on the treponemal complement-fixation reaction give good reports of this test. Thus, for example, Garson and Portnoy (1957) report that the treponemal complement-fixation test gives good reproducibility, is at least as sensitive in early syphilis as the conventional reagin tests, and has a greater value in confirming a diagnosis of early syphilis than the treponemal immobilization test (T.P.I.). According to these investigators, whilst agreement between the two tests is not absolute, almost complete agreement is attained in the non-treponemal reacting group of sera. These workers, however, do not mention the high percentage of sero-reactors amongst some coloured people. In Great Britain 62 per cent. of these patients' sera (mainly British West Indians) were found to react positively when tested by the T.W.R. This discrepancy may be due to differences in the geographical origin of these patients.

In March, 1957, my colleague, Dr. Whelan, and I published a preliminary report of a complementfixation test for syphilis, using mechanically disintegrated Treponema pallidum as the antigen (Price and Whelan, 1957). The present paper is concerned with the results obtained after one year's work with this test.

During the time under review (1957), a total of 7,930 sera were tested in parallel, using the T.W.R. and the standard lipoidal tests for syphilis (S.T.S.) as used in this laboratory (the Whitechapel Wassermann Reaction and Price's Precipitation Reaction). Whilst the results have not been analysed in detail, the general impression gained has been that there seems to be no reason to alter the opinion expressed in the original article concerning the results obtained by similar parallel testing of some 3,279 sera. This was that the T.W.R. seemed to be more sensitive and specific than the lipoidal S.T.S.

\footnotetext{
* Received for publication February 25, 1958.
}

\section{Results}

Special attention was devoted to the results of the following series of tests by the T.W.R.:

(a) 505 cerebrospinal fluids (C.S.Fs) in parallel with the S.T.S.

(b) 1,493 sera in parallel with the T.P.I. test.

(c) 509 sera from coloured patients.

(d) sera from special types of patients.

A short analysis of this work is reported in the following paragraphs.

Routine C.S.Fs. - The results of testing 505 cerebrospinal fluids in parallel (T.W.R. and S.T.S.) were interesting and significant. The results in 495 cases (98 per cent.) agreed, whilst ten ( 2 per cent.) did not. Of the disagreements, two (one from a G.P.I. patient and one from a patient suffering from tabes dorsalis) were T.W.R. positive S.T.S. negative, and eight were T.W.R. negative S.T.S. positive. Of the latter, seven were C.S.Fs from well-treated patients diagnosed as cases of latent syphilis but clinically inactive. The cell counts, protein estimations, and Lange reactions proved to be normal. The remaining patient was diagnosed as a case of disseminated sclerosis and his C.S.F. was reported on as follows: Cell count not done, Protein $60 \mathrm{mg}$. per cent., Lange reaction 112221000.

It would appear, therefore, that the T.W.R. is the more reliable test for cerebrospinal fluid.

Routine Parallel Testing of Sera by T.W.R. and T.P.I.-The behaviour of the T.W.R. and the T.P.I. when sera were tested in parallel was investigated using a total of 1,439 sera. Of these it was impossible to give a useful report on 102 because 77 (5.4 per cent.) were reported as no valid test (N.V.T.) with the T.P.I., $21(1.4$ per cent.) as anticomplementary with the T.W.R., and $4(0 \cdot 3$ per cent.) as both no valid test and anticomplementary. This left 1,337 sera of which the results could be 
studied and of these 1,106 (87 per cent.) agreed and 231 (13 per cent.) disagreed. A tentative evaluation of the disagreements is given in Table I.

TABLE I

- ANALYSIS OF DISAGREEMENTS

\begin{tabular}{|c|c|c|c|}
\hline \multicolumn{2}{|c|}{ Clinical Assessment } & $\begin{array}{l}\text { TWR - } \\
\text { TPI }+\end{array}$ & $\begin{array}{l}\text { TWR }+ \\
\text { TPI } \cdot-\end{array}$ \\
\hline \multicolumn{2}{|c|}{$\begin{array}{c}\text { Patients suffering from syphilis, all } \\
\text { stages, treated and untreated }\end{array}$} & 78 & 35 \\
\hline \multicolumn{2}{|c|}{ Patients suffering from yaws .. } & 6 & 11 \\
\hline \multicolumn{2}{|c|}{ 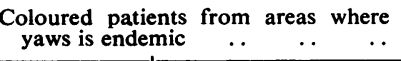 } & 3 & 37 \\
\hline \multirow{2}{*}{ Unclassifiable } & $\begin{array}{l}\text { (a) Probable } \\
\text { treponemal } \\
\text { tors }\end{array}$ & $\begin{array}{l}15 \\
(1 \cdot 1 \text { per cent. })\end{array}$ & 16 \\
\hline & $\begin{array}{l}\text { (b) Possibly trepone- } \\
\text { mal reactors, but } \\
\text { evidence insuffici- } \\
\text { ent }\end{array}$ & 12 & 18 \\
\hline
\end{tabular}

Most of the patients diagnosed as cases of syphilis had oldstanding treated infections and their serum reactions strengthened the impression that the T.W.R. is more sensitive to treatment than the T.P.I.; it remains to be demonstrated what value should be put on the results of T.P.I. positive "fast" sera.

The rest of the Table is self-explanatory, but it does seem that the difference in the incidence of probable non-treponemal reactions with either test is of little or no significance.

Routine Sera from Coloured Patients.-The frequency of T.W.R. sero-reactors when tests were performed on the sera of coloured patients was also investigated. In all, 509 sera were tested, and 315 (62 per cent.) recorded positive results. Of these, 163 (32 per cent.) were suffering from or had a history of treponematosis, 83 yaws, 80 syphilis, and in 152 (30 per cent.) there were no clinical signs or history of this infection. The remaining 194 (38 per cent.) were recorded as non-reactors.

Of the sera from coloured patients, 82 were selected at random and subjected to parallel tests with the T.P.I. Of these, fourteen (17 per cent.) failed to react with either test, whilst thirty (37 per cent.) were positive with both tests. Thus, both test results agreed in 54 per cent. of sera. Of the remainder, 33 ( 40.0 per cent.) were T.W.R. positive and T.P.I. negative, whilst five (6 per cent.) were T.W.R. negative and T.P.I. positive. The true significance of these positive T.W.R. reactions obtained when the sera of coloured people are tested has yet to be determined, and is at present under investigation. Suffice it to say that this test (T.W.R.) could be used as an aid in the diagnosis of yaws but cannot differentiate between this disease and syphilis.

Sera from Special Types of Patients Tested in Parallel with the T.W.R. and T.P.I. tests.-

(1) Antenatal Sera.-181 sera from antenatal patients were tested in parallel with the T.W.R. and T.P.I. reaction because of equivocal results obtained with the usual standard lipoidal tests. Of these, fourteen (8 per cent.) were reported as N.V.T. with the T.P.I. This left 167 sera to be compared; the results of 133 (80 per cent.) agreed (89 positive, 44 negative), and 34 (20 per cent.) disagreed. The disagreements are analysed in Table II.

TABLE II

DISAGREEMENTS IN ANTENATAL SERA

\begin{tabular}{|c|c|c|c|c|}
\hline \multicolumn{3}{|c|}{ Clinical Assessment } & $\begin{array}{l}\text { TWR - } \\
\text { TPI + }\end{array}$ & $\begin{array}{l}\text { TWR + } \\
\text { TPI - }\end{array}$ \\
\hline \multicolumn{3}{|c|}{ All stages of syphilis, treated and untreated } & 5 & 1 \\
\hline \multicolumn{3}{|c|}{ Coloured patients from yaws area } & 1 & 6 \\
\hline \multirow{2}{*}{ Unclassifiable } & \multicolumn{2}{|c|}{$\begin{array}{l}\text { (a) Probable non-trepone- } \\
\text { mal reactors } \ldots\end{array}$} & 5 & 10 \\
\hline & \multicolumn{2}{|c|}{$\begin{array}{l}\text { (b) Probable treponemal } \\
\text { reactors }\end{array}$} & 3 & 3 \\
\hline
\end{tabular}

Table II shows the anticipated pattern of results, e.g. the quicker effect of treatment on the positive T.W.R. and the greater incidence of positive T.W.Rs when the sera of coloured patients from yaws areas are tested. On the other hand, interpretation of the results is often conditioned by some difficulty in obtaining the necessary information about antenatal patients.

(2) Blood Donors.-Of the 42 patients tested in parallel with the T.W.R. and T.P.I. tests, 33 results were in agreement (positive 18, negative 15), seven disagreed, and two were reported as N.V.T. with the T.P.I. An analysis of the disagreements is shown in Table III. This small number of sera tested gives the usual pattern of results.

TABLE III

DISAGREEMENTS IN SERA FROM BLOOD DONORS

\begin{tabular}{c} 
Clinical Assessment \\
\hline $\begin{array}{l}\text { Patients suffering from syphilis, all stages, } \\
\text { treated and untreated }\end{array}$
\end{tabular}


(3) Haemolytic Anaemia.-The sera of fourteen patients suffering from this disease were tested in parallel with the T.P.I. test. Of these, eleven (4 positive, 7 negative) were in agreement, and three disagreed. Two of the latter were T.P.I. positive T.W.R. negative and were being treated with prednisone at the time of testing. The T.W.R. results might well be in accordance with the well-known action of cortisone on immunity reactions. The third serum in which there was no evidence of past or present syphilis was T.W.R. negative T.P.I. positive.

(4) Interstitial Keratitis.-The sera of 22 patients were tested in parallel (T.W.R. and T.P.I.), and eighteen (7 positive, 11 negative) results were in agreement. All four disagreements (T.W.R. negative, T.P.I. positive) were from oldstanding treated syphilitic patients.

\section{Conclusions}

A considerable amount of work has been done and 7,930 sera and 505 C.S.Fs have been tested in a preliminary evaluation of the T.W.R. As a result it seems reasonable to draw the following conclusions:

(1) The results of the tests are reproducible.

(2) The results of testing sera or cerebrospinal fluids are more sensitive and specific than when the standard lipoidal antigen is used.
(3) The T.W.R. appears to become positive sooner than the T.P.I. in early syphilis.

(4) The test has little advantage over other tests in established and untreated syphilis.

(5) The test is more sensitive in detecting positive reactions with the sera of coloured patients than the "classical tests" or than the TPI.

(6) There is no statistical difference in the results when the sera of non-treponemal reactors are tested by the T.W.R. and the T.P.I.

(7) The T.W.R. appears to respond more readily to antibiotic treatment than other tests, i.e. the T.W.R. usually becomes negative before the T.P.I. when clinical evidence of the disease has ceased to be apparent.

The T.W.R. appears to be a highly sensitive and specific reaction which well merits the attention of clinicians and serologists. The comparative ease with which it can be performed cannot be ignored and brings it into the realms of a routine procedure.

\section{REFERENCES}

Garson, W., and Portnoy, J. (1957). Publ. Hlth Lab. (Burlington, Vt),

Price, I. N. O., and Wheland, M. J. (1957). Brit. J. vener. Dis., 33, 18. 